\title{
Prevalence of HIVIAIDS and its associated factors among prevention of mother-to-child transmission (PMTCT) service users in Jinka town health institutions, south Omo zone, south Ethiopia
}

\author{
Wanzahun Godana ${ }^{1}$, Abraham Atta ${ }^{2}$ \\ ${ }^{1}$ Department of Public Health, College of Medicine and Health Sciences, Arba Minch University, Arba Minch, Ethiopia \\ ${ }^{2}$ South Omo Zone Health Department, Health Promotion and Disease Prevention Coordinator, Harar, Ethiopia
}

Email address:

Wanzanati2011@gmail.com(W. Godana)

To cite this article:

Wanzahun Godana, Abraham Atta. Prevalence of HIV/AIDS and its Associated Factors among Prevention of Mother-to-Child Transmission (PMTCT) Service Users in Jinka Town Health Institutions, South Omo Zone, South Ethiopia. Science Journal of Public Health. Vol. 1, No. 3, 2013, pp. 125-130. doi: 10.11648/j.sjph.20130103.13

\begin{abstract}
Background: According to the latest figures of the United Nations Agency for International Development/World Health Organizations (UNAIDS/WHO) 2007 AIDS Epidemic Update, an estimated 33.2 million people are living with Human Immune deficiency Virus (HIV). There was only $34 \%$ coverage for prevention of mother to child transmission. Of the estimated 2.5 million HIV-infected children under the age of 15 , well over $90 \%$ are thought to have been infected through mother to child transmission. Objectives: To assess prevalence of HIV and its associated factors among Prevention from Mother To Child Transmission (PMTCT) service users from Jinka Town Health Institutions, South Omo Zone. Materials and Methods: one year secondary data was collected retrospectively from the health facilities that were reported PMTCT in that year and analyzed using SPSS statistical package. Results: of a total of 960 clients received PMTCT service during the one year report. Based on the report $3.4 \%$ of the pregnant women were affected or sero-positive for HIV. HIV prevalence among counter male partners was $6.5 \%$. There was also missing some components of PMTCT services. Conclusion and Recommendations: HIV is still a major health problem among women of reproductive age. Preventive strategies should aim at partner tracing and risk reduction along full PMTCT program implementation is recommended.
\end{abstract}

Keywords: Prevalence, Mother to Child Transmission, HIV/AIDS

\section{Introduction}

Prevention of mother-to-child HIV transmission (PMTCT) is still the most effective intervention in fighting new HIV infections. Globally, Human Immune deficiency Virus (HIV) is the leading cause of death and disease for women of reproductive age worldwide and a major contributor to infant mortality among women between the ages of 15 and 44 years (1). Over 60,000 women died from HIV while giving birth in 2008 from a lack of appropriate maternal and HIV/AIDS services (2). In 2009, only 53\% of the pregnant women identified as HIV-infected worldwide received any Anti Retro Viral for PMTCT, resulting in approximately 370,000 new infant infections (3).

In sub-Saharan Africa, an estimated 22.5 million people were living with HIV at the end of 2009, including 12 million women and 2.3 million children. During 2009, an estimated 1.3 million Africans died from Acquired Immune Deficiency Syndrome (AIDS). Almost $90 \%$ of the 16.6 million children orphaned by AIDS live in subSaharan Africa (4). According to the latest data, significant progress has been made in delivering PMTCT of HIV services in low and middle income countries, however, much work remains to be done (3). Prenatally acquired HIV infection is associated with rapid progression of the disease and death, particularly in resource limited settings (5).

Scale-up of AIDS treatment and PMTCT services is helping to reduce child deaths (6). In Sub Saharan Africa (SSA), mother-to-child-transmission (MTCT) is contributing substantially to rising child mortality and 
shortages of human resources, making the quality of care substandard in the worst affected countries (7). Also MTCT remains a challenge in Ethiopia and the percentage of voluntary counseling and testing (VCT) users among pregnant women (PW) attending PMTCT clinic was $<10 \%$ in 2006 and almost $20 \%$ in 2008 (8).

A study from an urban area in Zimbabwe to assess the impact of routine antenatal HIV testing for preventing mother-to-child transmission of HIV found that of the 4551 pregnant women presenting for Ante Natal Care(ANC) during the first 6 months of routine HIV testing, 99.9\% were tested for HIV. (9)

A study in Ethiopia that examined the progress and an addressed need in access and utilization of PMTCT service showed that a significant progress had been made in the proportion of pregnant mothers who accepted HIV testing after receiving counseling services (10).

Also another Study conducted in Ethiopia from 2004 to 2009 The proportion of women who received pre-test counseling, testing and post-test counseling among new ANC attendees was $66.3 \%$ in 2004 based on the reports from the three sub-cities that started reporting in 2004. In 2005, following the PMTCT programme scale up to the rest of the sub-cities, the counseling and testing utilization dropped to $32.1 \%$. The poor utilization persisted till 2007 when only $50.7 \%$ of the new attendees received HIV counseling and testing. The PMTCT programme gained momentum in 2008 when the revised guidelines that incorporated routine opt-out testing offer came into effect. Utilization of HIV counseling and testing increased to $84.5 \%$ in 2009. The trend in receiving post- test counseling remained stable at high level across the years which imply that almost all the tested women collected their HIV test result (11).

A study from South Africa revealed that 3\% of the pregnant women who were found to be HIV negative in their first HIV testing during pregnancy became HIV positive in repeat test in late pregnancy, giving a $10.7 \%$ incidence per year. This indicated that women are at risk to acquire new HIV infection from their HIV positive partner anytime during pregnancy and even during breast feeding. Meanwhile, women who recently been infected with HIV are more likely to transmit HIV infection to their babies (12).

In the eastern and southern African region, including Ethiopia, $36-85 \%$ of the HIV positive individuals are believed to live with an HIV negative partner (13). HIV incidence is four times higher among pregnant women compared to their non-pregnant counterparts (14).

A retrospective study conducted in Ethiopia to examine the progress and an addressed need in access and utilization of PMTCT service showed that the prevalence of HIV among those pregnant mothers who underwent HIV testing had decreased from $8 \%$ to $2 \%$ within the reporting period 2006-2010. The pattern of reduction in HIV prevalence followed an exponential pattern. Although the prevalence had shown a significant reduction, the number of HIV positive pregnant mothers identified per year had increased from 4,172 in 2006 to 13,257 in 2010 . During the entire five-year period, a total of $42,195 \mathrm{HIV}$ positive mothers were identified out of the 1,462,565 mothers tested for HIV making the overall prevalence of HIV $2.9 \%$ (10).

In sub- Saharan Africa, out of 26 countries, only $50 \%$ of the HIV positive mothers had access to ARVS for Prevention of mother to child HIV transmission (15). To assess prevalence of HIV/AIDS and its Associated Factors among Prevention of Mother-To-child Transmission (PMTCT) Service Users in Jinka Town Health Institutions, South Omo zone, South Ethiopia.

\section{Methods and Materials}

Study area and Period: This study was conducted in South Omo zone. The study area is one of the fourteen zones in South Nation Nationality and Peoples' Region (SNNPR). This region was among the nine regions in Ethiopia. This region is among the region which has lowest economic growth. It is $750 \mathrm{KM}$ south of the main capital city of the country, Addis Ababa and $550 \mathrm{Km}$ away from the regional capital, Hawassa. The zone is located in $4.43^{\circ}$ $6.46^{\circ}$ North latitude \& $35.79^{\circ}-36.06^{0}$ South longitude. The climatic condition ranges from Dega to Kola which constituted $34.4 \%$ of the zonal climatic condition. According to the 2007 National Census the zonal total population was estimated to be 661550 and it was a home for 16 tribes, magnificent cultural diversity and afrotraditionalism.

According to the zonal Health Department Annual Report the health infrastructure was constituted by one zonal hospital, 27 functional health centers, 209 rural health posts and 11 urban health posts which was equivalent with the national set standard for which universal health coverage is achieved.

Currently the zone has with one general hospital which was serving the zone's total population of 678417. Starting from 2006 the Hospital has been giving integrated ANCPMTCT service for the pregnant women who have been follower of ANC service. As the national target, mothers who are pregnant expected to attend ANC and offered with PMTCT. And after, they are counseled the severity of the transmission of HIV from mother to child consequently results the death of child as well as the life of the mother was at risk. This study was conducted from 2010 to 2011

Source population: All pregnant women in South Omo Zone attending for PMTCT service and antenatal care

Study population: All pregnant women who attended PMTCT providing health institutions between time period 2010 to 2011. The study populations accordingly were all pregnant mothers with PMTCT \& antenatal care visits during the study period.

Inclusion and Exclusion criteria

Inclusion criteria: All ANC and PMTCT service followers who received the services with a completed 
record were included in the study.

Exclusion criteria: In the study period clients who attended for other services were not included in the study and PMTCT and ANC service users with incomplete record.

Study design: Cohort Analysis of PMTCT data was conducted on the recorded data of the Jinka Hospital and Health center in the year between 2010 and 2011

Sample size determination and sampling technique: The one year data (2010 to 2011) was used based on the availability of well-organized data.

\subsection{Study Variables}

Dependent variables: HIV prevalence among PMTCT service utilizes

Independent variables: The independent variables included: services related factors, maternal related factors, partner and child/infant related factors.

Data collection tools: For the relevance of the data a spread sheet was developed to collect data from the recorded registration book and patient card.

The one year data recorded on the patient's card that attended for ANC and offered PMTCT service was collected and organized according to the variables of this study.

Data collection procedures: variables for the study were first identified from client cards and PMTCT registration book. Recoding of the need variables was done to have valid and good result with a good quality data.

Data quality control: training was given for data clerks before data collection to assure the quality of collected data. And also close supervision of the data collectors during data collection time and cross checking the collected data.

Data management and data analysis procedures: Once the data was collected it was automatically entered in to a computer in prior developed data entry template and data was analyzed. Different statistical analysis was used to describe the study population. Binary logistic regression was used to identify the relationship between the dependent variable and independent variable. Significance level was set at 0.05 levels. Variable with $\mathrm{p}=0.2$ were included in subsequent step for further analysis.

Ethical considerations: Ethical permission of the research was secured from the zonal health department. All individual working in PMTCT and ANC clinic were informed about the study and participated in the study.

\section{Results}

\subsection{Socio-Demographic Characteristics}

The socio-demographic variables included in this study were age, residence, religion, occupation and marital status.

In this study a total of 960 pregnant women secondary records were collected and analyzed. Accordingly of the 960 pregnant women $835(87 \%)$ were married. The remaining $10(1 \%), 12(1.3 \%), 28(2.9 \%)$ were separated or divorced, widowed and unknown respectively.
A majority of the participants 749 (78\%) were urban dwellers; the remaining $211(22 \%)$ were rural. Their age characteristics' showed that the pregnant women 487 (50.7\%) were aged 25-34 years. The outstanding 15-24 years and above 34 years were contributed 403 (42\%) and $70(7.3 \%)$. This result shows that the clients' preference of health institution is hospital, $634(66 \%)$ (Table 1).

Table 1. Socio-demographic information of pregnant women who attended PMTCT service in Jinka town health institutions 2010 to $2011(n=960)$

\begin{tabular}{|c|c|c|}
\hline Characteristics & $\begin{array}{c}\text { Frequency } \\
(n=960)\end{array}$ & Percent \\
\hline \multicolumn{3}{|l|}{ Age } \\
\hline $15-24$ & 403 & 42.0 \\
\hline $25-34$ & 487 & 50.7 \\
\hline $34+$ & 70 & 7.3 \\
\hline \multicolumn{3}{|l|}{ Residence } \\
\hline Urban & 749 & 78.0 \\
\hline Rural & 211 & 22.0 \\
\hline \multicolumn{3}{|l|}{ Religion } \\
\hline Orthodox & 528 & 55 \\
\hline Protestant & 288 & 30 \\
\hline Muslim & 96 & 10 \\
\hline Others & 48 & 5 \\
\hline \multicolumn{3}{|l|}{ Occupation } \\
\hline House wife & 336 & 35 \\
\hline Government employee & 38 & 4 \\
\hline Merchant & 154 & 16 \\
\hline Farmer & 374 & 39 \\
\hline Others & 58 & 6 \\
\hline \multicolumn{3}{|l|}{ Marital status } \\
\hline Married & 835 & 87 \\
\hline Separated & 10 & 1 \\
\hline Widowed & 12 & 1.3 \\
\hline Unknown & 28 & 2.9 \\
\hline \multicolumn{3}{|l|}{ Health institution type } \\
\hline Hospital & 634 & 66 \\
\hline Health Center & 326 & 34 \\
\hline Total & 960 & 100 \\
\hline
\end{tabular}

\subsection{PMTCT Utilization}

Of the total pregnant women who attended the PMTCT service utilization $960(100 \%)$ were offered pretest counseling. Among these, 960 (100\%) offered for pretest counseling $96(10 \%)$ were refused to accept HIV testing and the rest $864(96.5 \%)$ were accepted to be tested. The result showed the positivity of the pregnant women who were tested for HIV (PMTCT service utilized) was 29 (3.4\%). And the remaining $835(96.6 \%)$ were negative. Of the total of 864 pregnant women who were tested for HIV and accepted post test counseling were $764(88.4 \%)$ and the remaining $100(11.6 \%)$ were no accepted post test counseling. The pregnant women who were identified to be sero-positive and received ARV prophylaxis were 26 $(89.6 \%), 2(6.9 \%)$ did not receive the service and one of the woman refused to receive the service. A majority, $714(74.4 \%)$ women were multipara, and 780(81.25\%) were above 20weeks gestational age (Table 2) 
Table 2. PMTCT utilization of pregnant women who attended PMTCT service in jinka town health institution in South Omo zone, SNNP 2010 to $2011(n=960)$

\begin{tabular}{|c|c|c|}
\hline Characteristic & $\begin{array}{c}\text { Frequency } \\
(n=960)\end{array}$ & Percent (\%) \\
\hline \multicolumn{3}{|c|}{ Number of pregnancies } \\
\hline Primigravida & 246 & 25.6 \\
\hline Multigravida & 714 & 74.4 \\
\hline \multicolumn{3}{|l|}{ Gestational Age } \\
\hline$<20$ weeks & 180 & 18.75 \\
\hline$>=20$ weeks & 780 & 81.25 \\
\hline \multicolumn{3}{|l|}{ Pretest counseling } \\
\hline Used & 960 & 100 \\
\hline Not used & 0 & 0 \\
\hline \multicolumn{3}{|c|}{ accepted HIV testing $(n=960)$} \\
\hline accepted & 864 & 90 \\
\hline Not accepted & 96 & 10 \\
\hline \multicolumn{3}{|c|}{ HIV test result $(n=864)$} \\
\hline Positive & 29 & 3.4 \\
\hline Negative & 835 & 96.6 \\
\hline \multicolumn{3}{|l|}{ Tested at this site } \\
\hline Yes & 864 & 90 \\
\hline No & 96 & 10 \\
\hline \multicolumn{3}{|c|}{ Tested at another site } \\
\hline Yes & 96 & 10 \\
\hline No & 864 & 90 \\
\hline \multicolumn{3}{|c|}{ Post test counseling $(n=864)$} \\
\hline Yes & 764 & 88.4 \\
\hline No & 100 & 11.6 \\
\hline \multicolumn{3}{|c|}{ Referred for care, treatment and support } \\
\hline Yes & 26 & 2.7 \\
\hline No & 2 & 0.2 \\
\hline Refused & 1 & 0.1 \\
\hline Not applicable & 931 & 97 \\
\hline
\end{tabular}

\subsection{Partner and child related services}

Concerning the partner and child related services, the date of appointment for ARV enrollment was 26(89.6\%); $432(45 \%)$ brought their partner for counseling and testing. Among those partners who came for counseling and testing, only $108(25 \%)$ were tested. Among the tested participants, $7(6.5 \%)$ and $103(95.45)$ were HIV sero positive and received the post test counseling respectively. Of the pregnant women who were counseled on child feeding options, 19(65.5\%) were counseled on exclusive breast feeding and $10(34.5 \%)$ were counseled on exclusive replace-mental feeding. There were 26(89.7\%) HIV exposed infants who received the ARV and $3(10.3 \%)$ did not received the service (Table 3 ).

Table 3. Partner and child related services among PMTCT utilizes in Jinka Town Health institutions, 2010-2011

\begin{tabular}{ccc}
\hline $\begin{array}{c}\text { Characteristics } \\
\text { Date of appointment for ARV enrollment }\end{array}$ & Frequency & Percent \\
Mentioned & 26 & 89.6 \\
Not mentioned & 3 & 10.4 \\
Brought partner for counseling and testing & & \\
Yes & 432 & 45 \\
No & 528 & 55 \\
Partner tested $(\mathrm{n}=432)$ & & \\
\hline
\end{tabular}

\begin{tabular}{ccc} 
Yes & 108 & 25 \\
No & 324 & 75 \\
Partners test result(n=108) & & \\
Positive & 7 & 6.5 \\
$\quad$ Negative & 101 & 93.5 \\
$\quad$ & & \\
Partner received result and post test & 103 & 95.4 \\
counseling(n=108) & 5 & 4.6 \\
Yes & & \\
No & 19 & 65.5 \\
Counseled on infant feeding option & 10 & 34.5 \\
EBF & & \\
ERF & 26 & 89.7 \\
HEI received ARV & 3 & 10.3 \\
Yes & & \\
No & 708 & 73.75 \\
Yes & 252 & 26.25 \\
\hline No & & \\
\hline
\end{tabular}

\subsection{The Prevalence of HIV}

The prevalence of HIV in this study was $3.4 \%$ among women $6.5 \%$ among men. The discrepancy may be attributed to different factors.

\subsection{The Bivariate Analysis}

The bi-variant analysis showed that HIV sero-status was not associated to most of the variables under consideration.

Table 4. showing the bi-variant analysis of HIV sero-status and the independent factors among PMTCT service Utilizes of Jinka Health institutions of South Omo zone 2010 to 2011

\begin{tabular}{|c|c|c|c|c|}
\hline \multirow{2}{*}{ Characteristic } & \multicolumn{2}{|c|}{ Sero-status } & \multirow{2}{*}{$\begin{array}{l}\text { OR (CI } \\
95 \%)\end{array}$} & \multirow{2}{*}{ P-Value } \\
\hline & Positive & Negative & & \\
\hline \multicolumn{5}{|l|}{ Age $(n=960)$} \\
\hline $15-24$ & 10 & 413 & $\begin{array}{c}0.68(0.28 \\
1.61)\end{array}$ & 0.64 \\
\hline $25-34$ & 16 & 451 & $\begin{array}{c}0.79 \\
(0.21,3.52)\end{array}$ & 0.71 \\
\hline $34+$ & 3 & 67 & 1.00 & \\
\hline \multicolumn{5}{|l|}{$\begin{array}{l}\text { Marital status } \\
\quad(n=960)\end{array}$} \\
\hline Married & 26 & 884 & 1.00 & \\
\hline Separated/divorced & 3 & 47 & $\begin{array}{c}2.17 \\
(0.51,7.69)\end{array}$ & 0.20 \\
\hline \multicolumn{5}{|l|}{$\begin{array}{l}\text { Health institution } \\
\qquad(\mathrm{n}=960)\end{array}$} \\
\hline Health center & 10 & 321 & $\begin{array}{c}1.00 \\
(0.47,2.30)\end{array}$ & 0.09 \\
\hline Hospital & 19 & 610 & 1.00 & \\
\hline \multicolumn{5}{|l|}{ Residence $(n=960)$} \\
\hline Rural & 5 & 202 & $\begin{array}{c}0.75 \\
(0.25,2.11)\end{array}$ & 0.56 \\
\hline Urban & 24 & 729 & 1.00 & \\
\hline $\begin{array}{c}\text { Antenatal care visit } \\
\qquad(n=960)\end{array}$ & & & & \\
\hline
\end{tabular}




\begin{tabular}{ccccc}
\hline 1st ANC visit & 26 & 892 & 0.38 & 0.11 \\
2nd ANC visit & 3 & 39 & 1.00 & \\
Sex & & & & \\
Male & 7 & 101 & $\begin{array}{c}2.00(0.77- \\
\text { F.93) }\end{array}$ & 0.10 \\
Female & 29 & 835 & 1.00 & \\
\hline
\end{tabular}

\section{Discussions}

According to the results of the study, HIV prevalence was high among both sexes. Acceptance of participant test after counseling was high for females. A significant proportion of HIV exposed infants, did not take the service. A majority of the ANC attendant mothers received some components of PMTCT services.

Prevalence of HIV in this study was $3.4 \%$ for females and $6.5 \%$ for males. This result was high when we compared it with national HIV prevalence which is $2.1 \%$. This may be due to the fact that HIV is more prevalent among pastoralist community where there are different tourists visiting and exposing to occupational risks and also due to the mobile nature of the pastoralist community.

Concerning PMTCT care nearly all had pretest counseling among other PMTCT service components. Prevention of Mother-to Child HIV Transmission is still the most effective intervention in combating new HIV infections. It estimated that over $90 \%$ of childhood HIV infections result from MTCT. Mere counseling on MTCT is not the effective way of PMTCT. When compared among mothers who provided with pre-test counseling, only $90 \%$ were tested. Other $10 \%$ refuses the test. This may also contribute to less reduction in Mother to child HIV transmissions.

Partner counseling and testing is one component of PMTCT. In this study, only 432(45\%) mothers brought their partner to HIV counseling and testing. Among these only $108(25 \%)$ were tested and the HIV prevalence was $6.5 \%$. This can also increases the likelihood of HIV infection among the newborns. There is also discordance in test result among the partners. This can also increases the chance of infecting a partner. Refusal for receiving test should also be considered for future intervention. Since males were not accepting tests, this may also affect the implementation of the program.

Concerning HEI service, $10 \%$ HIV exposed infants were not given the service. And also only $26 \mathrm{HIV}$ positive mothers were referred to care and support. Some of the mothers were refused the service. This indicted that the there is a need for intervention. Since the guideline for PMTCT required $100 \%$ service provision.

Nearly $3.4 \%$ of the women in the study were HIVpositive, indicating that HIV is still a major public health problem among women of reproductive age in Jinka Town Health institutions of South Omo Zone.

The prevalence observed $(3.4 \%)$, is similar to the prevalence of $7.3 \%$ described among women aged 15-49 years in Kilimanjaro region, in the recent Tanzania HIV/AIDS Indicator survey (16).

The HIV prevalence was greater among women aged 2534 years. This suggests that most infections occur among pregnant mothers as their age increases they are more likely to have children and hence the transmission of HIV from mother to child may be high(17).

Marital status characteristics were strong predictors for HIV in other previous studies. Pregnant mother who have no partner currently were more affected than compared to pregnant mothers who have had partner. This was may be due to mothers who have had no partner were practicing unsafe sex and have many sexual partners or may not encourage their sexual partner to use condom during sexual intercourse(18). As sexual partner increases it increases the chance to get HIV (19).

\section{Conclusions and Recommendations}

HIV is remains a major health problem among women of reproductive age. The implementation of PMTCT program in its full component coverage still needs intervention. Consequently some some eligible groups are missing the service. Therefore, preventive mechanisms against HIV prevention in pregnant women and in all aspects of reproductive health programs is of the utmost importance if we want to advance the prevention of HIV in women generally, and in the community at large. Other important preventive strategies should aim at partner tracing and risk reduction among partners to fully achieve the PMTCT targets.

\section{Acknowledgments}

Our heartfelt gratitude goes to South Omo Zonal Health Department Head Mr Abdela Alte for his support to participate in this research done in the zone.

We would like to thank all PMTCT workers for providing adequate information used for the purpose of research.

\section{References}

[1] United Nations General Assembly: Summary of the 2008 High Level Meeting on the Comprehensive Review of the Progress Achieved in Realizing the Declaration of Commitment on HIV/AIDS and the Political Declaration on HIV/AIDS Geneva; 2008.

[2] Knoll, R., M. Jake., F. Abraham., C.Wang. H. Rector., D. Alison., JL.Christopher, 2010 Neonatal, post neonatal, childhood, and under-5 mortality for 187 countries, 19702010: a systematic analysis of progress towards Millennium Development Goal 4. The Lancet, Vol.375

[3] World Health Organization (2010), Antiretroviral drugs for treating pregnant women and Preventing HIV infection in 
infants: towards universal access. Available http://whqlibdoc.who.int/publications/2010/9789241599818 _eng.pdf, 2013

[4] UNAIDS, 1999-2000.The impact of VCT. A global review of the benefits and challenges of testing Geneva: UNAIDS.

[5] Newell, ML., H. Coovadia, M. Cortina-Borja, N. Rollins, P. Gaillard and F. Dabis, 2004 Mortality of infected and uninfected infants born to HIV-infected mothers in Africa: a pooled analysis. Lancet; 364:1236-1243.

[6] Rotenberg, N., S. Kalibala., C. Baek and J.Rosen, 2003.programme recommendations for the prevention of mother - to - child transmit ion of HIV a practical guide for managers. New York: UNICEF.

[7] World Health Organization (WHO) PMTCT Strategic Vision 2010-2015 Preventing mother-to-child transmission of HIV to reach the UNGASS and Millennium Development Goals: Moving towards the elimina tion of pa edia tric HIV. Available

http://www.who.int/hiv/pub/mtct/strategic_vision.pdf, 2013

[8] Shaffer.N and M. Brewenke 2009 prevention of mother to child up date paper Washington, 2009

[9] Chandisarewa, W., Stranix-Chibanda L, Chirapa E, Miller A, Simoyi M, Mahomva A, Maldonado Y, Shetty AK: Routine offer of antenatal HIV testing ("opt-out" approach) to prevent mother-to-child transmission of HIV in urban Zimbabwe. Bulletin of the World Health Organization (WHO), 2007, 85:843-850. http://www.ncbi.nlm.nih.gov/pubmed/18038074?dopt=Abstr act

[10] Tilahu N.,Yoseph W. 2011 Analysis of the Prevention of Mother-to-Child Transmission Service utilization in Ethiopia: 2006-2010 Reproductive Health 2011, 8:6 http://www.reproductive-health-journal.com /content/8/1/6 pp1-8

[11] Alemnesh, H Mirkuzie., G. Hinderaker and O. Mørkve., 2010 Promising outcomes of a national program for the prevention of mother-to-child HIV transmission in Addis Ababa: a retrospective study BMC Health services Research, http://www. Biomed center.com/1472-6963/10/267 pp1-8

[12] Moodley, D., TM. Esterhuizen and T.Pather.2009 High HIV incidence during pregnancy: compelling reason for repeat HIV testing. AIDS (London, England)23(10):1255-9.

[13] HAPCO/GAMET: HIV/AIDS in Ethiopia - An Epidemiological Synthesis. Washington DC 2008

[14] Mukherjee.S., L. Ivers, F. Leander, O. Farmer and H. Behforouz., 2006 antiretroviral therapy in resource-poor settings decreasing barrier to access and promoting adherence, J Acquire Immune Deficiency Syndrome, Vol 43 Supp 1 pp 126.

[15] Palella, F., C. Arman., K. Buchacz., S. Cole., J. Chmiel., R. Novak.,... J .Brooks., 2009 the association of HIV susceptibility testing with survival among HIV-infected patient receiving antiretroviral therapy a cohort study, Ann. Intern.Med.Vol 151 no 2 pp 73-84

[16] OMI. Clients' perceived quality of PMTCT: Ugandan and Tanzanian Experience. January, 2011.

[17] Zuma K GE, Williams B, Lurie M: . Risk factors for HIV infection among women in Carletonville, South Africa. migration, demography and sexually transmitted diseases. 2003.

[18] EDHS. Ethiopian Demographic and Health 2011;1:56.

[19] Msuya SE. HIV among pregnant women in Moshi Tanzania: the role of sexual behavior, male partner characteristics and sexually transmitted infections. AIDS Research and Therapy 17 October 2006;3:27 20. 